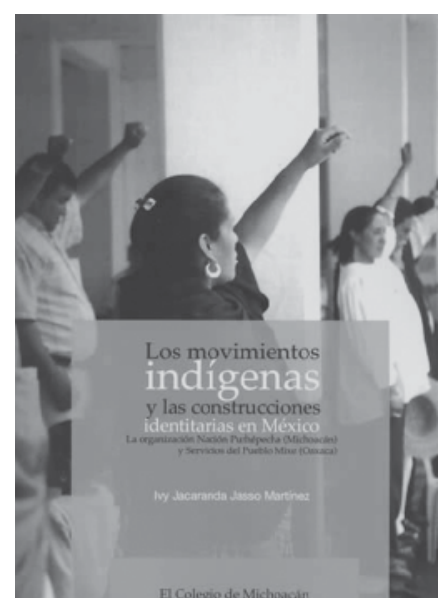

Identities and Indigenous

Movements in Mexico

JOSEFINA VIVAR ARENAS

El Colegio de Michoacán,

Zamora, Michoacán, México josefinavivar@gmail.com

Desacatos 50, enero-abril 2016, pp. 209-212

\section{Identidades y movimientos indígenas en México}

\author{
JOSEFINA VIVAR ARENAS \\ JOSEFINA VIVAR ARENAS
}

Los movimientos indígenas y las construcciones identitarias en México: la Organización Nación Purhépecha (Michoacán) y Servicios del Pueblo Mixe (Oaxaca)

IVY JACARANDA JASSO MARTíneZ, 2012

El Colegio de Michoacán, Zamora, 341 pp.

E

1 libro de Ivy Jasso Martínez estudia un tema poco explorado en la literatura sobre movimientos indígenas: la construcción de la identidad —o identidades étnicas — como recurso político para conformar organizaciones indígenas y encauzar sus demandas. En palabras de la propia autora, es un "estudio detallado de las organizaciones que forman parte del movimiento indígena en sus arenas políticas, para dar cuenta de la relación e influencia entre procesos de conformación de agentes políticos a través del reconocimiento y la construcción de su diferencia étnica” (p. 10). La investigación se enfocó en un estudio comparativo entre dos experiencias organizativas del movimiento indígena en dos estados: la Organización Nación Purhépecha, Tacuro, municipio de Chilchota, Michoacán, y Servicios del Pueblo Mixe, Santa Cruz Condoy, municipio de Quetzaltepec, Oaxaca, cuyos límites espacio-temporales son las propias organizaciones políticas y su red de relaciones - definidas como campo político — desde la década de 1970 hasta 2006. Ésta es otra aportación del estudio. Aunque las condiciones histórico-geográficas son diferentes, en ambos estados las organizaciones están discutiendo temas como la autonomía y la autodeterminación de los pueblos originarios. 
Como se planteó analizar un objeto de estudio en constante construcción, la identidad étnica, retomó la propuesta de McAdam, McCarthy y Zald (1999) y elementos de otras teorías para conformar herramientas que facilitan una aproximación más completa de los movimientos sociales, como oportunidades políticas, recursos movilizadores y procesos enmarcadores. Para Jasso Martínez, el modelo de McAdam, McCarthy y Zald consiste en lo siguiente:

Las oportunidades políticas muestran la interacción entre movimientos sociales y política institucionalizada. Se aprecian y evalúan a partir de cuatro aspectos vinculados entre sí: a) el grado de tendencia a la apertura del sistema político institucionalizado, b) la estabilidad en las alineaciones de las elites que definen determinadas líneas políticas, c) la posibilidad de contar con el apoyo de estas elites, d) la capacidad estatal para reprimir los movimientos sociales y su tendencia a hacerlo (McAdam, McCarthy y Zald, 1999: 25).

Los recursos movilizadores "se refieren a los 'canales colectivos tanto formales como informales, a través de los cuales la gente puede movilizarse e implicarse en la acción colectiva' (McAdam, McCarthy y Zald, 1999: 24). Éstas pueden analizarse por medio de las estrategias, alianzas, demandas y redes que forman los movimientos" (p. 25). Por último, en esta obra se entienden los procesos enmarcadores como "los esfuerzos estratégicos conscientes realizados por grupos de personas en orden de forjar formas compartidas de considerar el mundo y a sí mismas que legitimen y muevan a la acción colectiva” (p. 26). Éste es el elemento mediador entre las oportunidades y las estructuras de movilización. Es un sistema de significados compartidos que privilegia la defensa de las identidades en la confrontación por espacios de decisión en el país y que dotan de sentido a la acción colectiva.
Alrededor de estos tres ejes de análisis se organiza el contenido del libro. En el capítulo I se habla de los movimientos indígenas y las construcciones identitarias; en el capítulo II, de las oportunidades políticas de las organizaciones indígenas; en el capítulo III, de las estrategias y recursos de dos organizaciones del movimiento indígena en Michoacán y Oaxaca; el capítulo IV se centra en los procesos enmarcadores en la Organización Nación Purhépecha y Servicios de Pueblo Mixe, y el capítulo V retoma la lucha a partir de las identidades étnicas en las organizaciones estudiadas.

Jasso Martínez pone mayor énfasis en los procesos enmarcadores, dado que su interés analítico se centra en estudiar cómo los movimientos indígenas politizan su etnicidad. Es decir que estos movimientos privilegian las demandas relacionadas con la defensa de la diversidad cultural y se concentran en su identidad étnica. Se puede decir que en el marco de los movimientos indígenas, en la actualidad, ser indígena es, también, un recurso político, sin olvidar que la filiación étnica permanece más allá de la disputa por su reconocimiento.

De acuerdo con ello, "la identidad étnica puede concebirse como un capital étnico o un tipo de capital simbólico ('pueblos explotados', 'ecologistas natos', 'conservacionistas', 'minorías étnicas', etcétera) que permite interactuar a las organizaciones indígenas" (p. 36). Esto quiere decir que la identidad étnica puede convertirse en un recurso en pugna en el terreno político. En cuanto a los marcadores de identidad, los grupos étnicos recurren a múltiples rasgos para resaltar su identidad particular, unos más importantes que otros, de acuerdo con los significados que las personas les asignan y su circunstancia concreta —idioma, vestimenta, historia, prácticas sociales, vida cotidiana, acceso a la tierra, color de la piel, fiesta, sistema de cargos, apellido, visión del tiempo y el espacio, etc. - (p. 36). Jasso Martínez analiza estos marcadores de identidad indígena a partir de la aplicación de una encuesta realizada en las 
localidades estudiadas. Esto le permitió acercarse a los rasgos distintivos que las personas "de a pie" consideran más importantes de su ser indígena y los confrontó con los discursos que los líderes de las organizaciones difunden en sus intentos por mantener la cohesión del grupo, atraer simpatizantes y movilizar actores.

Estas identidades son complejas, cambiantes, se reinterpretan y se movilizan constantemente en función del escenario donde se despliegan. No obstante, parece que la disputa más urgente a resolver para las organizaciones es contra el Estado: “aceptar que los indígenas se nominen ellos mismos, obliga al Estado a aceptarlos como sujetos políticos” (p. 40) y a que puedan crear derechos. Para Jasso Martínez, el grado de compatibilidad y empatía que presentan las organizaciones en términos de su adhesión a una identidad indígena común se verá reflejado en la efectividad de su acción colectiva. Las organizaciones indígenas investigadas parecen estar conscientes de este recurso y ponen en práctica estrategias para asegurar y consolidar su cohesión —reuniones, foros de discusión, desplegados, programas de radio, difusión en medios-.

Un aspecto central del análisis es que se aleja de posiciones esencialistas acerca de la construcción de las identidades étnicas, puesto que el estudio pone el acento en los procesos mediante los cuales las identidades colectivas se erigen también a partir de "la utilización de atributos que 'otros' les han impuesto a las poblaciones indígenas (por ejemplo, el ser ecologistas, poseedores de conocimientos profundos, que son producto de una visión romántica). Esto implica un manejo selectivo de rasgos y

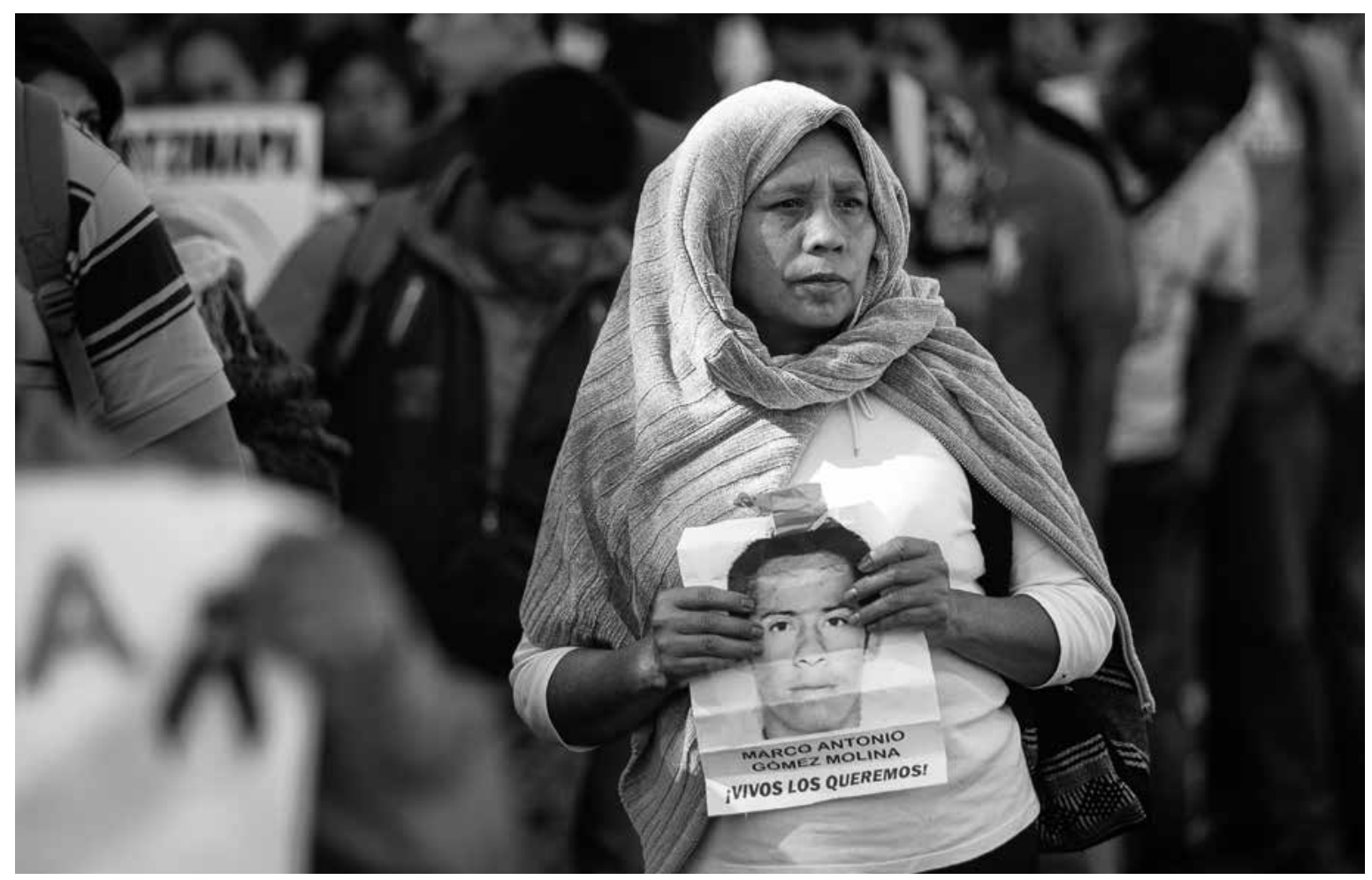

PROMETEO LUCERo - Padres de los estudiantes normalistas de Ayotzinapa desaparecidos en Iguala, Guerrero, marchan durante la protesta conmemorativa del 2 de octubre de 1968. Ciudad de México, 2015. 
discursos frente a diversos agentes" (p. 243). Estos rasgos pueden llegar a relacionarse o imbricarse con las acciones colectivas que dan sentido de membresía dentro de las comunidades - cumplimiento de faenas, ocupación de cargos en el sistema político, cumplimiento de cargos en las fiestas, entre otros-, con el conjunto de significados míticos e ideológicos que comparten y con los lazos afectivos y de parentesco (p. 252).

El uso del concepto "marcadores de identidad" permite el análisis de los rasgos principales a partir de los cuales estas organizaciones sociales indígenas construyen su identidad colectiva. Entre los más relevantes, y que los propios agentes encuentran como fundamentales para su ser indígena, están: a) las prácticas y valores comunitarios: el sistema normativo comunitario, cargos cívicos y la asamblea, "usos y costumbres", la propiedad comunal; b) "el idioma" (p. 288), y c) los símbolos: la bandera purhépecha, que representa a las cuatro regiones, su fuerza y su valor; y para los mixes, el guerrero Cong Hoy, un héroe mítico que representa la fuerza y lucha de este grupo étnico, su valentía y furia.
Ambas organizaciones intentan generar marcos de motivación que involucren y muevan a los integrantes y no integrantes. Participan en la elección de rasgos marcadores para construir un ser ideal que en la práctica se percibe más conflictivo. Las organizaciones son cuestionadas por especialistas, ya sean "maestros purhépechas o mixes, investigadores mestizos, abogados indígenas, etcétera” (p. 291-292), por lo que la "autenticidad" buscada por los líderes de estas organizaciones en el discurso y en las acciones emprendidas son impugnadas constantemente. Con este enfoque, el análisis abre una visión completa y global de las influencias que posibilitan que la acción colectiva se movilice, pero también permite comprender la emergencia, el rumbo y tal vez el destino de esas acciones colectivas, al atender no sólo a los aspectos organizativos del movimiento social en sí, sino su dinámica, su relación con otros agentes, con sus bases de apoyo, sus prácticas y discursos, y las condiciones sociales y políticas en las que aparece. Por último, se destacan en esta obra tanto la revisión bibliográfica exhaustiva como la incluisión de mapas y fotografías que ilustran los marcadores de identidad étnica. D

\section{Bibliografía}

McAdam, Doug, John McCarthy y Mayer Zald (comps.), 1999, Movimientos sociales: perspectivas comparadas, Istmo, Madrid. 